\title{
Amerikaanse toestanden
}

\author{
De eerste slag in de strijd om commerciële televisie
}

\section{Leo Akkermans}

In I95s organiseerde de gemeente Rotterdam de tentoonstelling Nationale Energie Manifestatie I955 (E5S). Daar zou ook televisie te zien moeten zijn. De Nederlandse omroepen gingen ervan uit dat zij dat vanzelfsprekend zouden verzorgen. Dat bleek buiten de waard gerekend. Het bedrijfleven had, op initiatief van Philips, de stichting TVss in het leven geroepen, die ook op de tentoonstelling televisie wilde tonen - maar dan commerciële. Reconstructie van de eerste slag tussen 'Hilversum' en de commercie.

Bij de Vara zal men in 1955 vreemd hebben opgekeken toen in een speciale uitgave van Het Vrije Volk, het dagblad waar de omroep een sterke binding mee had, het publiek werd opgeroepen toch vooral niet bang te zijn voor commerciële televisie:

\begin{abstract}
'Men behoeft zich door die reclame niet te laten afschrikken, want verstandige firma's begrijpen heel goed dat reclame-programma's met alleen maar reclame uit den boze zijn. Daarom beperkt men zich zeer sterk tot een enkele aanduiding in het programma, of laat men een opvoering voorafgaan door een paar maal tien seconden waarin, meestal door de omroepster, dan gezegd wordt wie het programma uitzendt."
\end{abstract}

Het krantje verscheen dagelijks tijdens de tentoonstelling Nationale Energie Mani- festatie 1955 (E55). De gemeente Rotterdam wilde ermee laten zien wat er allemaal, tien jaar na de oorlog, was bereikt en opgebouwd. Handel, nijverheid en industrie waren prominent vertegenwoordigd door onder meer bankwezen, кLM en Spoorwegen. Tentoongestelde thema's luidden onder andere 'Groei en bloei van stad en platteland', 'Van oertijd tot ruimtevaart' en 'Woonwijk van morgen'. De echte gouden koets stond er te pronk en er was zelfs een kritische afdeling, waar duidelijk gemaakt werd dat Nederland veel te vol en veel te nat was en dat je dus maar beter kon emigreren. $^{2}$

Naast al dat leerzaams en nuttigs had organisator Jac. Kleiboer, die voor Rotterdam eerder de succesvolle Ahoy-tentoonstelling had verzorgd, een groot aantal attracties naar het terrein gehaald. De voornaamste daarvan was de televisie. In I95I was het nieuwe medium in Bussum officieel van start gegaan. Iedereen had ervan gehoord maar echt vertrouwd was het publiek er niet mee. Dat valt af te leiden uit het geschatte aantal van vijftienduizend verkochte toestellen ${ }^{3}$ en uit de correspondentie tussen de Nederlandse Televisie Stichting (NTS) en het bestuur van de E55. De NTS was verheugd geweest de mogelijkheid te krijgen op de tentoonstelling televisie te laten zien, want zo kon het publiek meer vertrouwd raken met televisie. ${ }^{4}$ Dat laatste 
was beslist nodig, want televisie had nog de status van kermisattractie. De door Het Vrije Volk verzorgde dagkrant bevatte veel 'nieuwtjes' over de televisie. Een verslaggever constateerde dat bezoekers zich opstelden voor een televisiecamera en dan naar de dichtstbijzijnde monitor renden om zichzelf op het scherm te kunnen zien. Hij besloot zijn bijdrage: 'Televisie is actueel en direct. Dàt moeten de mensen leren."

\section{Verontwaardigd}

Als gezegd was de NTS ingenomen met de mogelijkheid op de E55 aanwezig te zijn. Piet de Vlaam, hoofd Technische Dienst van de NTS, verwoordde de inzet van zijn bedrijf toen hij schreef:

\section{'Indien naast onze representatieve aanwezigheid op E5s onze activiteit daar een grotere publieke belangstel- ling voor televisie weet te wekken, dan zal dit ongetwijfeld het verlangen naar méér en betere producties in de periode, onmiddellijk op Es 5 volgend, stimuleren. ${ }^{6}$}

De Vlaam liet er direct op volgen dat de voorgestelde uitbreiding van de technische faciliteiten voor het derde kwartaal zouden moeten vervallen en er in snel tempo technisch personeel moest worden aangetrokken. NTs-secretaris Wim Rengelink had eerder het bestuur van de E55 laten weten dat de tentoonstellingsplannen grote kosten met zich meebrachten. Hij zou het dan ook op prijs stellen wanneer organisator Kleiboer een bespreking wilde organiseren 'met alle belanghebbenden'. Als handelsvertegenwoordiging stelde hij de Nederlandse Vereniging van Radiodetailhandelaren voor. De industrie moest in zijn ogen vertegenwoordigd worden door Philips en Erres.

De NTS wist dat er op 3 januari door het E55-bestuur een zendmachtiging was aangevraagd. Als vanzelfsprekend werd aangenomen dat die bestemd was voor de omroepen. De verbazing was dan ook groot toen op 3 januari de Volkskrant en (drie dagen later) Telegraaf berichtten dat enkele grote bedrijven de regering toestemming hadden gevraagd voor een belangrijk experiment: proefnemingen met commerciële televisie op de E55. Het ging hier om de stichting Televisie '55 (TV55), die door Philips was voorzien van een geschikte directeur: J.M. Brandel, theater- en filmproducent in Parijs, die voor een half jaar naar Nederland was gehaald. Vóór de oorlog was hij directeur geweest van Philips in Frankrijk en tijdens de oorlog directeur van het Londense Vrij Nederland. ${ }^{8}$ Het andere bestuurslid was W.F.T. Hunger, secretaris van de Kamer van Koophandel in Rotterdam. Vijf dagen later reageerde Rengelink op een persconferentie verontwaardigd. Terwijl de NTS onderhandelde met het tentoonstellingsbestuur was er een stichting in het leven geroepen zonder dat de NTS ergens vanaf wist.

J. Hasper, gemeentesecretaris van Rotterdam en bestuurslid van E55 begon een waar offensief tegen de NTS. Eind januari klaagde hij dat de NTS slechts op een paar dagen en dan ook nog maar op enkele uren, programma's kon uitzenden. Dat was een groot bezwaar, vond Hasper, attracties moesten op alle dagen en gedurende een groot aantal uren beschikbaar zijn. Daar kwam nog bij, aldus het bestuurslid, dat de tentoonstelling niet voor het grote aantal ontvangers kon zorgen die over het hele terrein verspreid opgesteld moesten 
worden om zoveel mogelijk bezoekers 'het fenomeen' te laten aanschouwen. Philips was benaderd maar was niet in staat te zorgen voor èn toestellen èn een zender èn een studio. 'Om het kostenvraagstuk op te lossen is overwogen of wellicht reclame de uitzendingen op E55 lonend zou kunnen maken."

\section{Bijspringen}

Op I9 januari kwamen de omroepbestuurders, die samen de NTS vertegenwoordigden, voor een bespreking naar Rotterdam, waar zij werden ontvangen in de trouwkamer eerste klasse van het stadhuis. ${ }^{10}$ Men bezichtigde de maquettes en liet zich voorlichten over wat er allemaal te doen zou zijn op de tentoonstelling. Daarop verklaarden de NTS-bestuurders dat zij onder de indruk waren van de grootse opzet en dat zij gaarne bereid waren 'zowel per radio als per televisie in grote opmaak gewag te maken van de tentoonstelling E55." "Tot zover was het allemaal gezellig geweest in de trouwkamer. Dat veranderde toen de NTs duidelijk maakte dat men in Bussum geschrokken was van de persberichten over commerciële televisie. Als dat zou doorgaan, deed de NTS verder niet meer mee. De NTS had er principieel bezwaar tegen dat die commerciële programma's ook buiten het terrein opgevangen zouden kunnen worden - en dat daarmee niet langer gesproken zou kunnen worden van louter tentoonstellingstelevisie. En verder vreesde de NTS dat er artiesten zouden worden gecontracteerd die al voor de verschillende omroepen werkten. Op de vraag waarmee men wel kon instemmen, liet Rengelink doorschemeren dat 'de radioindustrie', zoals hij Philips aanduidde, wel bij zou moeten springen en dat daar natuurlijk wel wat reclame tegenover zou moeten staan. ${ }^{12}$ Schoorvoetend werd door de bestuurders van de omroepen geopperd dat er geen bedenkingen waren tegen een documentair filmpje met een aankondiging dat de uitzendingen door een of andere firma werden aangeboden.

'Ook niet tegen een filmpje zoals men wel in de bioscoop ziet waarbij aan het slot de aandacht wordt gevestigd op een bepaald product. Maar overwegende bezwaren heeft de NTS tegen culturele uitzendingen, zoals bv: Hier komt het Concertgebouworkest, aangeboden door... en zelfs tegen een crooner, die ook voor de televisie kan verschijnen. ${ }^{13}$

Een maand later, 3 maart 1955, kwamen de twee stichtingen bijeen. Tv55 was van mening dat de NTs juist blij moest zijn met de nieuwe stichting, die 'een propagandamiddel voor de NTS kunnen zijn'. ${ }^{14}$ Twee dagen later stuurde de NTS een brief naar minister Cals van oc\&w met het dringende advies om de door Rotterdam gevraagde zendmachtiging niet te verlenen:

'Wetende hoezeer de Regering en de
volksvertegenwoordiging er steeds op
hebben aangedrongen de verzorging
van televisieprogramma's te leggen in
handen van culturele, niet op winst
gerichte instellingen, die in de radio-
omroep bewezen hebben zich van
hun verantwoordelijkheid bewust te
zijn, zou het ons ten zeerste verbazen
indien thans een andere weg zou wor-
den gevolgd.'

KRO-voorzitter (tevens voorzitter van de NTS) Kors onderstreepte op een vergade- 
ring dat de NTS zou afhaken wanneer er op de E55 commerciële televisie vertoond zou worden. Hunger van TV 55 gaf daarop E55voorzitter Kleiboer het advies daar niet rouwig om te zijn. De NTS zou toch met niet veel anders komen dan 'een saai aftreksel van commerciële televisie door bijv. de fabricage van zeeppoeder of klompen te laten zien, zonder dat er merknamen genoemd mochten worden. ${ }^{16}$

Hunger draaide er in die bijeenkomst niet omheen: het doel van TV55 was voor de makers ervaring opdoen en voor de toeschouwers kennismaken met commerciële televisie. Hij raadde het E55-bestuur van harte aan van 'twee kwade posten' de beste te kiezen en dat was natuurlijk de commerciële televisie. Vergezeld van een perscampagne over het vraagstuk commerciële televisie, zou het een belangrijke attractie kunnen worden waar de E55 alleen maar voordeel van zou hebben 'omdat iedereen zich zal willen vergewissen wat nu deze verboden vrucht eigenlijk is. ${ }^{17}$ Fijntjes voegde hij er tot slot aan toe dat hij informatie had dat de regering in het algemeen en minister Cals in het bijzonder, helemaal niet zo geporteerd waren van een monopoliepositie van de NTS. Hij deed de regering de suggestie om de NTS een hint te geven zich in haar eisen te matigen en om aan TV 55 de ruimte te geven.

Nog diezelfde dag ging er een brief van NTS-secretaris Rengelink naar E55-bestuurder Hasper. Rengelink schreef dat de NTS bereid was medewerking te verlenen aan het uitzenden van programma's op de E55 - als tenminste Philips zorgde voor 'voldoende reproductiemogelijkheden'. De
'Van maandag $\mathrm{t} / \mathrm{m}$ vrijdag van 14.00 tot 18.00 , vier programma's van 50 min. bestaande uit : I) is min. journaal; 2) Is min. "live" programma; 3) Io min. interviews met bezoekers; 4) ro min. diverse filmpjes. Daarna io min. pauze en vervolgens herhaling van bovengenoemd programma. Op zaterdagavond een programma uit de studio op de Es5 in plaats van uit Bussum. ${ }^{18}$

Over commercie werd niet gerept. Het NTs-bestuur ging er waarschijnlijk vanuit dat het allemaal wel mee zou vallen en de organisatie toch wel voor de omroepen zou kiezen.

\section{Oneerlijke concurrentie}

Het E55-bestuur vond de verhouding tussen NTS en TV 55 echter 'bizonder onaangenaam'. Op 3 maart kwamen de bestuurders van E55 en TV55 bij elkaar in het kantoor van de Rotterdamse Kamer van Koophandel. Er was maar één vraag. Hoe nu verder? Kleiboer maakte duidelijk dat E55 in principe had ingestemd met de plannen van TV 55 ,'omdat zij steunden op de nationale industrie', maar dat de stichting wel wat te ver gegaan was. De NTS was wantrouwig geworden en dat was in hoge mate versterkt doordat Brandel, voorzitter van TV 55, had gesproken over commerciële televisie. Misschien, zo suggereerde Kleiboer, dat de NTS de zaak nog eens zou willen bespreken met 'de industrie' en dat dan wellicht de verhouding met TV 55 wat zou kunnen verbeteren. Het E55-bestuur drong erop aan verder niet meer over commerciële televisie te praten. Aangeraden werd tegenover de NTS de term 'tentoonstellingstelevisie' te gebruiken. ${ }^{19}$ 
Het E55-bestuur zat met de kwestie in de maag en stuurde snel een aardige brief naar de NTS om te bedanken voor de programmavoorstellen die de NTS op ro februari had gestuurd. Die voorstellen wilde het tentoonstellingsbestuur graag aanvaarden, al moest er wat betreft de onderlinge samenwerking nog wel het een en ander geregeld worden. In deze brief werd de commerciële stichting niet één keer genoemd. Per expresse kwam op 7 maart het antwoord van de NTS: 'Uw brief draagt niet bij tot opheffing van de gerezen moeilijkheden.' De NTS handhaafde haar aanbod van programma's, maar dan moest de term commerciële televisie worden vervangen door tentoonstellingstelevisie. 'De uitzendingen daarvan zullen zich dienen te beperken tot directe reclame-uitzendingen. ${ }^{20}$

De omroepen hadden er kennelijk geen zin meer in. Op 8 maart, de dag nadat de boze brief was verstuurd, werd er een persconferentie belegd in Amsterdam. Rengelink zette het voor de verzamelde pers nog eens op een rijtje: commerciële televisie legt noodgedwongen bij het samenstellen van programma's andere maatstaven aan dan wenselijk is. Als een predikant waarschuwde hij zijn gehoor: 'Er is nog maar één groot voorbeeld van commerciële televisie en dat is Amerika en dat noopt niet tot navolging.' Hij was bereid toe te geven dat de ontwikkeling van 'reclame-televisie' in Europa misschien anders zou gaan dan in de Verenigde Staten, toch wist hij het zeker: commerciële televisie moest 'met omzichtigheid en voorzichtigheid worden benaderd. $^{21}$

De NTS had geen bezwaar tegen reclametelevisie op het E55-terrein, mits dat maar tentoonstellingstelevisie zou zijn. Tegen de pas opgerichte stichting TV 55 hadden de omroepen wel bezwaar: wat die ging doen was geen echte commerciële televisie! Dit argument oogstte alom verwondering. Rengelink lichtte zijn stelling toe. Wat TV55 wilde gaan doen op de tentoonstelling zou worden beschouwd als een echt experiment en dàt was volgens de NTSsecretaris beslist niet reëel. 'Met Tv5s krijgt men geen inzicht in wat commerciële televisie is.' De studio was gratis, de technische apparatuur veel goedkoper dan in werkelijkheid en iedere dag andere nieuwe programma's was op een tentoonstelling ook niet nodig. En het publiek was, nog steeds volgens Rengelink, niet het gewone publiek: 'Men geeft voorstellingen voor misschien zo'n drie miljoen bezoekers en niet voor de normale kijkers.' Hij besloot zijn uiteenzetting met de vrees dat TV55 erop uit was na de tentoonstelling te blijven aandringen op commerciële televisie. Op een vraag van een journalist of de NTS de belangrijke gebeurtenissen van de E 55 toch ging uitzenden, antwoordde hij: 'Waarom niet? Dat gaat in elk geval gewoon door.' De NTS was in feite bang dat wanneer zij gedurende de drie maanden dat de tentoonstelling duurde, niet met een dagelijks programma zou komen, TV 55 dat gat zou vullen met door reclame betaalde uitzendingen. 'Drie miljoen maken dan kennis met gesponsorde programma's, zal dat geen invloed hebben!?' riep de secretaris van de Nederlandse Televisie Stichting vertwijfeld uit en hij gaf zelf het antwoord:

'Natuurlijk wel, maar de zaak is niet reëel, na de tentoonstelling kan TV55 niet veel verder gaan, want dan richten zij zich niet tot drie miljoen mensen, maar tot 25.000 of 30.000 gezinnen. Ik weet niet veel van reclame 
maar ik stel me toch voor dat bedrijven zich zullen afvragen of dat wel loont! (...) Commerciële televisie gaat miljoenen kosten. Men moet beginnen er miljoenen in te steken en dàt zal toch niemand doen!?'2z

Het klonk alsof Rengelink het verschijnsel commerciële televisie wilde verdedigen tegen het verdraaide beeld dat TV55 ervan zou geven. De omroepen hadden geen idee hoe reclametelevisie er uitzag; er was alleen zorg: geen Amerikaanse toestanden! Had Rengelink in de persconferentie niet zelf gezegd dat er goed gelet moest worden op Engeland, omdat daar geëxperimenteerd ging worden met reclame op televisie? ${ }^{23}$

Eigenlijk had men in Bussum geen idee van wat de commercie met televisie zou kunnen doen. Op de persconferentie had Rengelink eerder gezegd dat de NTs gesponsorde programma's op zichzelf niet zo'n geweldige ramp vond. Programma's van de NTS moesten echter gefinancierd worden volgens de regeringsvoorschriften. Dus was er in de ogen van de NTS sprake van oneerlijke concurrentie:

'Wij kunnen geen dure artisten uit het buitenland laten komen om hen in de dure avonduren te laten optreden. Wij komen op de tentoonstelling naast (reclame)programma's die wel duur kunnen zijn, omdat zij dertig maal worden uitgezonden.'

\section{Noodweer}

Minister Cals stelde op 16 maart de NTs gerust. Het verlenen van de zendvergunning aan E55 betekende niet dat commerciële televisie ingevoerd zou worden: 'In geen enkel opzicht wordt vooruitgelopen op de vraag, of in Nederland commerciële uitzendingen zullen worden toegelaten.' ${ }^{24}$ Twee weken later, 30 maart, schreef E55 de NTS ook een brief. Daarin betreurde de organisatie dat de beide stichtingen niet tot een akkoord waren gekomen, 'zodat Uw vriendelijk aanbod van io februari niet zal kunnen worden geëffectueerd.' Geen NTS-programma's dus, geen technici en televisieregisseur uit Bussum. Philips stuurde Wil van Vlerken als hoofd Techniek naar de tentoonstelling. De regisseur was een opmerkelijke naam, met wie Van Vlerken nog had samengewerkt bij Philips Experimentele Televisie: Erik de Vries. Hij was net uit de Bussumse televisiewereld gestapt en dus beschikbaar voor de E55. Chef cameraman was de bekende cineast Theo van Haren Noman.

Op I8 mei verrichtte koningin Juliana de openingsceremonie. De NTS zou het allemaal rechtstreeks uitzenden. Het stormde die dag echter en de regen viel met bakken uit de lucht. En, zoals wel vaker gebeurde bij een buitenreportage bij noodweer, ging alles wat fout kon gaan, fout. Tijdens de rede van E55-bestuurslid Ernste kon de NTS nog in beelden voorzien door filmfragmenten te tonen waarop de Maas te zien was. Toen tot overmaat van ramp de nerveuze commentator dwars door de woorden van Juliana heen praatte, werd maar besloten er een punt achter te zetten. Een half uur vóór het geplande einde werd de uitzending gestaakt. Natuurlijk werd aan opzet gedacht, maar de fout lag bij de PTT, die verantwoordelijk was voor de verbindingen. ${ }^{25}$

Op de tentoonstelling, die duurde tot 3 september, kregen de bezoekers dagelijks commerciële televisie te zien. Mies 
Bouwman presenteerde in de E-55studio. Het publiek kon ook op een van de driehonderd toestellen die verspreid over de tentoonstelling waren opgehangen zien wat er allemaal werd uitgezonden. Dat waren twaalf programma's per dag. In de eerste maand interviewde Wim Ibo medewerkers van het populaire radioprogramma FAMILIE DOORSNeE (sponsor: R.S. Stokvis en $\mathrm{Zn}$ ). Er was een soloprogramma van de conferencier Cees de Lange (sponsor: Esso). Verder een soloprogramma van actrice Hetty Blok (met dank aan: Elias textiel). Dan sponsorden de Gezamenlijke Levensverzekeringen een instructief programma van het Rode Kruis getiteld DONOR VAN DE DAG. De Nieuwe Rotterdamse Courant en het Algemeen Dagblad verzorgden nieuwscommentaren. Joop Geesinks Dollywood maakte een poppentheater (sponsor: Unilever). Er was een muzikaal amusementsprogramma (gesponsord door Lucas Bols) en een wat serieuzer muziekprogramma waarin leerlingen van het conservatorium optraden (gesponsord door Philips). Deze programma's kwamen rechtstreeks uit de studio, waar ook Heintje Davids zo'n zestig keer optrad. Daarnaast werd een film met Juliette Greco uitgezonden (waarvoor Laurens Sigaretten in de beurs tastte), de KLM-film DE VLIEGENDE HOLLANDER en Wim Kan in een door Polygoon gefilmd soloprogramma (met dank aan: Vredestein Rubber). ${ }^{26}$ Het ging om amusementsprogramma's van negen minuten, met ervoor en erna een reclamespot van dertig seconden. Bij het poppentheater was de reclame in de tekst verwerkt, en in de documentaire WANDELING DOOR ROTTERDAM waren reclames opgenomen van winkeliers. De uitzendingen begonnen om één uur 's middags met aankondigingen van Mies Bouwman. Na elke tien minuten volgde er een reportage van het tentoonstellingsterrein. 's Avonds waren er langere voorstellingen met, wat aangeduid werd als gezinsprogramma's. Ieder programma werd in principe een maand lang herhaald. Dat was geen bezwaar omdat tenslotte de tentoonstelling iedere dag nieuwe bezoekers trok.

\section{Einde attractie}

Op 3 september sloot de tentoonstelling en was het afgelopen met de commerciële televisie. 'O, wat zijn daar toch veel boze woorden over gevallen', schreef De Telegraaf. De krant vroeg Brandel, die op verzoek van Philips genegen was geweest TV55 te leiden: 'Als er iets van commerciële tv in Nederland gaat komen neemt $u$ dan de leiding op u?' Nee, dat zag de zakenman niet zitten. Hij had het met plezier gedaan maar verdere ambities had hij niet, want erg hoog sloeg hij de kansen van commerciële tv in Nederland niet aan. Brandel ging weer naar Parijs: 'Wij hebben hier niets willen voorbereiden, alleen iets willen demonstreren. ${ }^{27}$

Het Nipo verrichtte onder Rotterdamse televisiebezitters die de commerciële programma's thuis hadden ontvangen en anderen die de televisie op het tentoonstellingsterrein hadden gezien, een onderzoek. Van de thuiskijkers vond 66 procent de reclameprogramma's aardig. 73 Procent was voor invoering van commerciële televisie. De andere ondervraagden waren verdeeld. Zeventien procent vond de uitzendingen aardig, maar driekwart had geen oordeel. 43 Procent van deze groep was voor reclame in normale uitzendingen. Het Nipo concludeerde dat televisiereclame door een 
meerderheid werd gewaardeerd. In de pers werd die conclusie als 'vrij voorbarig' bestempeld. Er was, zo betoogden journalisten, maar een beperkt aantal kijkers ondervraagd en de objectiviteit en algemeenheid werden bekritiseerd omdat het programma op de E55 beperkt was geweest. Door de herhalingen was het aantal sponsors klein geweest. De programma's hadden er, aldus de kranten, wellicht anders uit gezien als men dagelijks met iets nieuws had moeten komen en dan waren de antwoorden op de enquête waarschijnlijk anders geweest. ${ }^{28}$ De Volkskrant kopte: 'Reclame op beeldscherm moet haar kansen nog krijgen'. Ook deze krant vond de vertoning van commerciële televisie op de E55 meer een attractie dan een voorbeeld. ${ }^{29}$

Ruim drie miljoen bezoekers had de tentoonstelling getrokken. 350.000 Nieuwsgierigen en belangstellenden hadden het nieuwe medium in de studio bekeken. De Tijd twijfelde of het reclame-experiment een vervolg zou krijgen. Volgens deze krant was er tijdens de E55 een hausse geweest in de verkoop van televisietoestellen, en niet alleen in Rotterdam. Er was dan ook alle reden voor tevredenheid:

'Want nergens nog heeft het Nederlandse publiek in zo grote getale kennis kunnen nemen van het modernste van alle publiciteitsmiddelen, de televisie, als op de monstertentoonstelling, de E55. ${ }^{30}$

\section{Noten}

1 Het Vrije Volk, speciale E55-uitgave, 1955.

2 Brochure E55 emigratie-stand, in: Gemeente Archief Rotterdam (verder: GAR).

3 Verslag bespreking TV55 en E55, 3 maart 1955, in: GAR.
4 Aantekening bijeenkomst besturen NTs, E55 en TV55, in: GAR.

5 Het Vrije Volk, speciale E55-uitgave, 1955 .

6 Brief P. de Vlaam aan A.H. van de Veen, commissaris voor de techniek in het NTSbestuur, 3 februari 1955, in: Centraal Archief NOB (verder: CA-NOB).

7 Brief J.W. Rengelink aan J. Kleiboer, 27 december 1954, in: CA-NOB.

8 Aether, april 1995 .

9 Aantekening J. Hasper 21 januari 1955, in: GAR.

Io De aanwezigen waren de heren: Broeksz (Vara), Kors (KRO), Quarles van Ufford (Avro), Rengelink (Vara, NTs-secretaris), Van der Veen (NCRV) en Weisglass (VPRO).

II Aantekening J. Hasper, 21 januari 1955, in: GAR.

12 Verslag bespreking tussen TV55 en E55, 3 maart 1955, in: GAR.

13 Brief NTS Io februari 1955, in: GAR.

I4 Verslag bespreking tussen TV5s en E55, 3 maart 1955, in: GAR.

Is Brief s maart 1955, in: CA-NOB.

16 Verslag vergadering tussen NTS, E5s en TV 55 , 10 februari 1955, in: GAR.

17 Ibidem.

18 Brief NTS aan J. Hasper to februari 1955, in: GAR.

19 Verslag bijeenkomst TV5S en E55, 3 maart 1955, in: GAR.

20 Brief 7 maart 1955, in: GAR.

21 Verslag persconferentie NTs, 8 maart 1955, in: GAR. Veertig jaar later denkt Wim Rengelink er nog altijd hetzelfde over: 'We hebben hier helaas nu op televisie Amerikaanse toestanden!' (Rengelink tegen auteur, september 1995).

22 Verslag persconferentie NTS, 8 maart 1955 , in: GAR.

23 Veertig jaar later voegde Rengelink nog iets toe aan de officiële lezing: 'We moesten natuurlijk vijf verschillende omroepen op een rij krijgen, en de ene omroep was wat minder tegen dan de andere.' Overigens lukte dat toch wel aardig, 'omdat alle omroepen TV55 wantrouwden' (Rengelink tegen auteur, september 1995).

24 Brief 16 maart 1955, in: $\mathrm{CA}-\mathrm{NOB}$. 
25 Aether, april 1995.

26 Elsevier, 16 april 1955.

27 De Telegraaf, 20 mei 1955.

28 Maasbode, 8 september 1955 .

29 De Volkskrant, 14 september 1955.

30 De Tijd, 27 augustus 1955. 